\title{
Anadolu Kadınında Ezilmişliğin İtibarı
}

\author{
Pınar Kızılhan ${ }^{1}$
}

\begin{abstract}
$\ddot{O} z$
Anadolu kadını, sosyal ortamda ikinci planda kalmaktadır. Eril egemen kültürde, kadın ne kadar çok cefa çekerse toplumda o kadar çok itibar göreceği pekiştirilmektedir. Kadının toplumsal kimliği örselendikçe, kadın şiddete uğradıkça mağduriyeti üzerinden çevresinde kendine bir yer bulmaya çalı̧̧ır. "Ben çok acı çektim", "O da bir şey mi, benim yaşadıklarımı dinle." gibi ifadeler sorgulamadan benimsedikleri yaşam tarzı oluverir. Hastalanınca, yaptığ işlerin üzerine kalacağı korkusunu duyanların ise gerek evde gerek yakın çevrede kadına ilgiyi bir anda artırması, bir anlamda çekilen cefaya toplumun olumlu bakışını yansıtır. Nerede olduğunun daha az sorgulandiğg ortam ya yakın komşusu ya da hastane olabilmiştir. Bazıları dışarı çıkmaya öykünse de onaylanmadiğl ve onaylayamadiğından kendini geliştirmekten yana değil, acınmaktan yana elde edilen itibar daha makbulmüş gibi gelmeye başlar. Hakkın yiyen güce ses çıkarmaması öğrenilmiş çaresizliğidir. Yaşanan bu baskı, uyuşturucu gibi kadının hareketini sosyal ortamda felç eden kapalı bir kültür inşa etmiştir. Kadının dünyası daraldıkça, birlikte yaşamaktan da uzaklaşılmaya başlanır. Kadına yönelik bu aldırlşsız, suskun, ilgisiz tutum ve ortam yoksunluğu acıma ve acındırma üzerinden bir kültürün oluşmasına neden olmuştur. Uygar kişiliğin koşulu ve etkin vatandaşlığın gereği olarak kırsalda ve kentte kadının varlığl, toplumsal yaşamı tamamlayan bir özne olmalıdır. İlgi alanlarına göre farklı sosyal ortamlarda statü ve rol almanın önünün açılması, ev yaşamının dışında kadının emeğinin özgürleşmesi gerekmektedir.
\end{abstract}

Anahtar Sözcükler: Anadolu kadını, Ortam yoksunluğu.

\section{The Esteem of Being Insulted for Woman of Anatolia}

\begin{abstract}
Woman of Anatolia is of secondary importance in the social surroundings. Inmale-dominant society, it is supported that how much woman suffers, she is respected so much. Woman tries to gain a place in society via her damnification as long as her identity is crumpled, she is exposed to violence. The statements such as "I have suffered a lot"; "Big deal, listen to what I have lived"become their life styles which they internalize with out questioning. When they become sick, the ones who are afraid of taking the burden of her jobs, begin to increase their regard towards her. In one sense this shows the positive view of society toward ssuffering. The case in which she is less questioned where she is, is either her close neighbour or hospital. Although some are going out, it is not approved or she doesn't approve.

Here the esteem gained being insulted starts being more acceptable than improving herself. Being not object to the power being unfair to her is her learned helplessness. This oppression creates a closed culture paralysing woman's movement in society like narcotics. As woman's World becomes smaller, she becomes elianated to living together.Theattitude of beingin different, silent, unconcernedtowards woman and lack of surrounding which has caused to create a cultureby way of ruth and making other shave mercy. The existence of woman in the urban and rural are as should be a subject completing social life as a provition of civilized personand by force of effective citizenship. It should pave the way for woman's having statue and roles in different social surroundings as regards to her pursuits and woman's labor should be made liberal outside of domestic life.
\end{abstract}

Keywords: Woman of Anatolia, Lack of Surrounding

1 Dr. Ankara Üniversitesi Eğitim Bilimleri Fakültesi OSAE Türk Dili ve Edebiyatı Eğitimi ABD Eposta: pinar.kizilhan@mynet.com 


\section{Giriş}

Edmund Husserl tarafından geliştirilen ve bir kavram olarak Hegel tarafindan kullanılan fenomenoloji, bireylerin dünyayı ve kendi gerçekliklerinin nasıl yorumlandığı ile ilgilenir. Husserl, olguların temeline inerek insan bilincinin önemi üzerinde durur, olayları (görünüşleri) bireyler tarafından 'doğrudan doğruya' algılandığı şekilde inceler. Buna göre fenomenoloji, bireylerin olayları, durumları nasıl algıladıklarını anlamaya çalışır. Ayrıca fenomenoloji, bireylerin "olduğu gibi kabul edileni” niçin öyle kabul ettiğini, nasıl bir süreçle edindiklerini inceler.

Fenomenolojinin bir yöntem olarak kullanılması Alfred Schutz tarafından geliştirilmiştir. Schutz, anlamın toplumsal düzlemde nasıl oluştuğunu çözümlemeyi amaçlamaktadır. Bu çözümleme, toplumsal gerçekliğin oluşma sürecini gün yüzüne çıkartacaktır. Schutz, anlamın özneye özgü bir ürün olduğunu savunur. Birey, anlamını paylaşabilmek amacıyla, onu iletişimsel bir materyale dönüştürmektedir, böylece anlam nesnelleşmektedir. Anlam, toplumsal unsurlar arasında tedavül ettikçe, bireyler tarafından öznel yüklemelere maruz kalmaktadır. Bu özelliği ile anlam, özneler arası bir özellik arz etmektedir. Bu da sürekli olarak, öznelerin her seferinde yeniden, 'anlam' bağlamında etkileşimini zorunlu kılmaktadır. Çünkü anlam, tedavül etme süreci içinde, öznelere özgü boyuta indirgendikçe, iletişimsel materyal olma özelliğini kaybetmektedir. Anlama ilişkin yeniden ortaklık oluşturabilmek için onu yeniden nesnelleştirmek gerekmektedir. Böylece anlam toplumsal tedavül süreci içinde sürekli yeniden üretilmektedir (Hekman 1999: 46-48, Akt., Anık, 2006).

Weber'in insan eyleminin öznel anlamlarca belirlendiği yargısı benzer şekilde Schutz'a göre de eylemcinin gerçekleştirdiği eyleme ilişkin iki tür anlamlandırmadan söz edilebilir. Birincisi, yorumlayıcının zihninde gerçekleşen nesnel anlamlandırma; ikincisi, eylemcinin zihninde yer alan öznel anlamlandırmadır. Öznel anlamlandırma, sağduyuya dayanır. Eylemcinin kendi eyleminin anlamını kendisi yükleyerek yarattığı dünyaya saf deneyimin özgün dünyası; başkalarının değer yargılarına göre gerçekleşen eylem alanına da gündelik yaşam dünyası denilmektedir. Sosyoloji için sorun, hem bu süreçlerin hem de farklı kişilerce sağduyu dünyasının nasıl gerçekleştirildiğinin bilinmesidir. Diğer bir deyişle sorun, dışımızdaki dünya hakkındaki bilinç üretme biçiminin değil, kendi başına saf zihniyetin (puremind), bilinç üretme işleminin nasıl gerçekleştiğini veya bilincin soyut kurallarını bulmaktır (Erbaş, 1992, s. 159).

Schutz'a göre toplumsal dünya özneler arası bir dünyadır. Toplumsal dünyada insanların algıladığı düzenin, yani özneler arasılı̆̆ın temelleri, sağduyu bilgisi, tipleştirme ve karş1lıklılıktır. Schutz'un 'sağduyu bilgisi' adını verdiği bilgi, toplumun üyelerinin ortak olarak sahip olduğu ve gündelik yaşamın sürmesi için gerekli olan bilgi birikimidir. Bakış açılarının karşılıklılı̆̆ı, aksine inanmak için bir neden yoksa bireylerin toplumsal dünyadaki olay ve eylemleri kendileri nasıl anlıyorsa diğer bireylerin de aynı şekilde anlayacakları varsayımıdır. Diğer bir deyişle yaşadığımız toplumsal dünyada ilişkiler sistemimizi paylaşan herkesin belirli olgu ve kavramları ortak olarak doğal, iyi ve doğru olarak kabul etmesidir. Schutz, metodolojisini, Weber'in bilim felsefesine olan ilgisine dayandırır. Weber'in 'verstehen' 'öznel anlayış' kavramını kullanan Schutz, bireyin günlük hayat durumlarına atfettiği değeri ve anlamı önemser. Gündelik hayat özneler arası olarak kurulur. Ona göre bireyler "ortak bilgi stoku” içinden aldıkları kabullerle hareket ederler ve dünyayı, onlara toplumsal gruplar tarafindan verilen tipleştirmeleri ya da ideal tipleri kullanarak inşa ederler. Araştırmacı, bireylerin etkileşim süreci içinde paylaştı̆̆ 1 anlamları kavramak ister. Çünkü kişilerin öznel algısı nesnel sonuçlar üretmektedir. 
Kendi benliğini inşa eden birey, bilgi stoğunda yer alan kaynaklara başvurur. Bu kaynaklar; Bourdieu (1986) 'ya göre ekonomik, kültürel ve sosyal sermayedir. Ekonomik sermaye, ekonomik kaynaklar anlamına gelir. Toplumsal sermaye, toplum içerisindeki ilişkiler bütününü yansıtır. Kültürel sermaye ise eğitim yoluyla öğrenilmiş tüm kabulleri, davranış kalıplarını, kısacası toplumun özünü içerir. Her bireyin sahip olduğu sermaye miktarı ve çeşitliliği etkileşimde görünür olmaktadır. Etkileşim esnasında bireyler hakkındaki düşünceler onların ekonomik, sosyal, kültürel sermaye kaynaklarına dayanılarak oluşmaktadır. Bourdieu'ya göre toplum, sürekli yeniden yapılanan alanlardan oluşmaktadır. Bunlardan sosyal sermaye kişilerin saygınlık ve donanımlarıdır (Çeğin vd.: 2007). Literatürle ilişkili olarak, kadınların toplumdaki, saygınlığı, itibarları sosyal sermaye kaynağı olarak değerlendirilebilir.

Soner (2011) "yap1 ve fail ilişkisinden hareketle ataerkil ideoloji ve toplumsal cinsiyet etkileşimini anlamak" adlı makalesinde, kadının, toplumsal hayatın her alanında edilgen bir konumda, üreten değil sadece ilişkilerin, rollerin taşıyıcısı ya da yeniden üreticisi konumunda yer aldığını ve en önemlisinin de kadının bu durumun farkına varamadığını belirtmektedir.Yazar, kadının ataerkil ideolojinin ona yüklediği bütün sınırlılıkları, gündelik hayatı içinde durmaksızın yeniden ürettiğini ancak çoğu zaman bunu bilinçli olarak yapamadığını eklemektedir. Kadın, bu durumu fark etse de o kadar alışmıştır ki, karşı çıkmaz. Kadınların toplumsal hayatın her alanında ötekileştirildiği, ikincil konuma itildiği, ataerkil ideolojinin baskı ve engellemeleriyle karşılaştığı ve çoğu zaman bu durumun farkında olmadığı ya da bu duruma karşı çıkmadığ 1 belirtilmektedir. Özgürleşebilmeleri, mücadele edebilmeleri için de bütün bu gizli ilişkileri açığa çıkararak, sorgulayarak, yeniden kurmak zorunda oldukları açıktır.

Kadın sosyal ilişkiler içerisinde sosyal sermaye kaynağından faydalanmaktadır. Kadına özgü olarak, kadın için, eski ya da yeni kadın arkadaşlarının dostluğu son derece değerlidir. Bu dostluklar erkekler arasındaki ilişkilere benzemez; erkekler, kendilerine özgü fikir ve tasarılarla, birer birey olarak alışverişte bulunurlar; kadınlık yazgısının genelliği içine kapanmış olan kadınlarsa birbirlerine dolaysız bir suç ortaklığı ile bağlıdırlar. Birbirlerinden bekledikleri ilk şey, ortak evrenlerinin olumlanmasıdır (De Bouveoir, 1979).

$\mathrm{Bu}$ çalışmada, kadınların gündelik hayatın içinde, kendi yaşamlarından anlam çıkarmada kullandıkları yorumlar incelenmiştir.

\section{Araştırmanın Amacı}

$\mathrm{Bu}$ araştırmanın amacı, Ankara ili, Keçiören, Altındağ, Mamak ilçelerinde yaşayan alt ve orta sosyo-ekonomik düzeydeki ev kadınlarının gündelik yaşamlarında düzen ve anlamı nasıl yarattıklarına odaklanılarak benlik algılarının analizini yapmaktır. Ev kadınların sosyal ortam alanındaki sübjektif ve kültürel yönlerini, rol ve görevlerini ortaya koymayı, karşılaşılan sorunları ve bunlara yönelik çözüm önerileri geliştirmek bu araştırmanın amacını oluşturmaktadır.

Problem: Ankara ili, Keçiören, Altındağ, Mamak ilçelerinde yaşayan alt ve orta sosyoekonomik düzeydeki ev kadınları gündelik yaşamlarında düzen ve anlamı nasıl yaratmaktadırlar? Benlik algıları nasıldır?

Alt Problem 1. Gündelik yaşamınızda evde en çok zaman nerede geçirilmektedir?

Alt Problem 2. Gündelik yaşamınızda evin dışında, kimlerle ve nerede geçirilmektedir? 
Alt Problem 3. Gündelik yaşamınızda evin dışında buluştuğunuz kadınlarla en çok ne üzerine sohbet/ konuşma yaparsınız?

Alt Problem 4. Gündelik yaşamınızda şehir/kent merkezlerine ne sıklıkla gidersiniz? Gidiş amacınız nedir?

Alt Problem 5. Gündelik yaşamda evde kendinizi değerli ve özel hissettiğiniz zamanlar hangi zamanlardır?

\section{Yöntem}

Araştırmanın amacına yönelik olarak nitel araştırma deseni kullanılmış ve amaçlı örnekleme yöntemlerinden maksimum çeşitlilik örnekleme tekniği ile her ilçeden 8'er kişilik üç farklı grup ev kadını ile odak grup görüşmesi yapılmıştır.

Araştırmanın veri toplama sürecinde çeşitli ilk ve orta öğretim okullarının Rehberlik ve Psikolojik Danışma Servislerinden araştırmaya katılacak kadın velilerin gönüllülük esasına dayalı olarak seçilmesi ve uygun mekanlarda araştırma soruları yöneltilmiştir.

\section{Katılımcilar}

Tablo 1. Formları değerlendirilmeye alınan katılımcıların demografik özellikleri

\begin{tabular}{llll}
\hline Özellikler & & $\mathrm{f}$ & $\%$ \\
\hline & & & \\
Yaş & $35-45$ & 15 & 62.5 \\
& $46-50$ & 6 & 25 \\
& 51 ve üzeri & 3 & 12.5 \\
& & \\
Ĕ̆itim Durumu & İlköğretim 1. Kademe & 2 & 8.3 \\
& İlköğretim 2. Kademe & 7 & 29.2 \\
& Lise & 14 & 58.3 \\
& Üniversite (MYO) & 1 & 4.2 \\
\hline TOPLAM & & 24 & 100 \\
\hline
\end{tabular}

\section{Verilerin Toplanması}

Araştırmanın amacına yönelik nitel araştırma deseni amaçlı örnekleme yöntemlerinden maksimum çeşitlilik örnekleme tekniği ile her ilçeden 8'er kişilik üç farklı grup ev kadını ile odak grup görüşmesi yapılmıştır.

Odak grup görüşmeleri nitel veri toplamada önemli bir işleve sahiptir. Grup görüşmelerinde sorulara verilen yanıtlar gruptaki bireylerin birbirleriyle etkileşimleri sonucu oluşur. Yani grup dinamikleri sorulara verilen yanıtların kapsamını ve derinliğini etkileyen önemli bir etkendir (Yıldırım ve Şimşek, 2013, s.179). Odak grup görüşmeleri, '1lımlı ve tehditkar olmayan bir ortamda önceden belirlenmiş bir konu hakkında algıları elde etmek amacıyla dikkatle planlanmış bir tartışmalar serisi' olarak tanımlanabilir. Belirli bir yerleşim bölgesinde,örneğin, kadınların sosyo-kültürel sorunları vb. 
araştırma konularını çalışmak isteyen araştırmacılar değişik örnekleme yöntemlerini de işin içine katarak kısa sürede yüzlerce katılımcıya ulaşabilir(Yıldırım ve Şimşek, 2013, s.180).

Kruger ve Casey (2000; akt., Yı1dırım ve Şimşek, 2013) iyi yazılmış odak görüşme sorularının şu özelliklere sahip olması gerektiğini belirtir:

1. Sohbet tarzına uygun informel ya da günlük dil kullanımına uygun,

2. Katılımcıların kullandığı ve tanışık olduğu sözcük dağarcığını içermeli,

3. Öz ve tek hedefli olmali.

Alt problemlerden hareketle ev kadınlarının benlik algısını analiz etmeye ilişkin odak grup görüşme formu Tablo 2'de sunulmaktadır:

\section{Tablo 2. Odak Grup Görüşme Formu}

Giriş: Araştırma amacı hakkında bilgi verildi, tartışma sürecine ilişkin bazı temel uyulması gereken kurallar açıklandı. Görüşmenin yaklaşık 1.5-2 saat süreceği tekrarlandı.

\section{Lütfen isminizi söyleyip kendinizi kısaca tanıtır mısınız?}

1. Gündelik yaşamınızda evde en çok zamanınız nerede geçiyor?

2. Gündelik yaşamınızda evde işleriniz yokken, zamanınızı evin dışında, kimlerle ve nerede geçiriyorsunuz?

3. Gündelik yaşamınızda evin dışında buluştuğunuz kadınlarla en çok ne üzerine sohbet/konuşma yaparsiniz?

Sonda: Konuştuğunuzda karşınızdaki kadınlar tarafından en çok dinlenildiğinizi hissettiğiniz ve diğer kadınlar konuştuğunda en çok ilgiyle dinlediğiniz konular hangileridir?

Sonda: Bu konuları konuşmanızın sebepleri ne olabilir?

4. Gündelik yaşamınızda şehir/kent merkezlerine ne sıklıkla gidersiniz? Gidiş amacınız nedir? Sonda: Şehir merkezlerine kimlerle gidersiniz?

5. Gündelik yaşamınızda kent/şehir merkezine kendi başınıza yalnız gider misiniz?

Sonda: Neden şehir merkezine yalnız gidersiniz/gitmezsiniz?

Kaygı hissetmeden kent/şehir merkezine gittiğiniz oldu mu? Olduysa sebebi?

6. Gündelik yaşamınızda evde kendinizi değerli ve özel hissettiğiniz zamanlar hangi zamanlardır?

7. Gündelik yaşamınızda çevre, akraba ve komşularla ilişkilerinizde kendinizi özel hissettiğiniz zamanlar nasil olmaktadır? 


\section{Verilerin Analizi}

Kadınların benlik algılarının analizine ilişkin olarak yaşadıkları ortamın sübjektif yönlerini, rol ve görevlerini ortaya koymayı, karşılaşılan sorunları ve bunlara yönelik çözüm önerilerinin ele alınması amacıyla odak grup görüşmesi yoluyla elde edilen veriler ileti ölçütleri temel alınarak çözümlenmiştir. Kategoriler analizin ilerleyen aşamalarında araştırmacı tarafından ortaya çıkarılmıştır. Araştırmanın amacına bağlı olarak sözcük, tema, tümce gibi analiz birimleri kullanılmıştır. Araştırma verileri üç aşamada analiz edilmiştir: (1) Verilerin düzenlenmesi (Konu hakkında kategoriler ve temalar belirleyebilmek amaciyla verilerin kodlanması) (2) Verilerin özetlenmesi (Bilgilerin kategoriye göre kümelendirilerek her bir kategoriye tema bulunması) (3) Bulguların tanımlanması ve yorumlanması (Kategoriler arasındaki ilişkilerin belirlenmesi ve genellemelere gidilmesi).

\section{Bulgular ve Yorum}

1. "Gündelik yaşamda evde en çok zaman nerede geçirilmektedir?"

Katılımcılar, çoğunlukla evde en çok yemek ve temizlik işleri için mutfak ve banyoda zaman geçirdiklerini belirtmektedir. Ek olarak, dinlenmek için oturma odasında televizyon izleyerek zaman harcamaktadır.

Sonda: Ne tür programlar izlersiniz?

Katılımcıların çoğu, yemek ve kadın programları, dizi, nadiren de olsa ana haber izlediklerini ifade etmektedirler.

Sonda: Evde herhangi bir şey okur musunuz? Gazete, kitap vb.

Katılımcıların çoğu, okumaya vakitleri olmadığını belirtmektedirler.

2. "Gündelik yaşamda evin dışında, kimlerle ve nerede zaman geçirilmektedir?"

Katılımcılar genelde, yakın akraba kadınları, aynı yöre, köy, hemşeri ve diğer komşu kadınları ile genelde evlerde zaman geçirmektedirler. Kadınlar ilgi duydukları herhangi bir hobilerinin olmadığını belirtseler de evdeki kişilerin ve evin ihtiyacını karşılamak amacıyla elişi, örgü yaptıklarını belirtmektedirler.

3. "Gündelik yaşamda evin dişında buluştuğunuz kadınlarla en çok ne üzerine sohbet/konuşma yaparsinı??"

Katılımcılar genelikle çocukların okulları, dersleri, sınav hazırlıkları, ev işleri; yemek tarifleri, geçmiş, şimdiki sıkıntılar sebepleri, gelecek kaygısı ve yaşamsal zorluklar hakkında konuşmaktadırlar.

Sonda: Konuştuğunuzda karşınızdaki kadınlar tarafından en çok dinlenildiğinizi hissettiğiniz ve diğer kadınlar konuştuğunda en çok ilgiyle dinlediğiniz konular hangileridir?

Katılımcılar çoğunlukla kendilerinin en çok dinlenildiklerini düşündükleri konunun, kadın olarak kendilerinin yaşadığı ve kendilerine yapılan şiddet, dışlanma, baskı ve yaşadıkları kayıpların olduğunu belirtmektedir. Kendilerinin en çok ilgiyle dinledikleri konunun ise şiddet görmüş, olumsuzluklar yaşayan kişilerin söyledikleri olduğunu belirtmişlerdir. Katılımcıların sıklıkla yaptıkları değerlendirmeler şöyledir:

Komşumun ya da diğer kadınların, kocasının kendisini dövmesi, çocukların bundan çok korkması, yüzünün, gözünün şişmesi, morarmasından dolayı bir hafta on gün dışarı çıkmaktan utanması. 
Sonda: Şiddet görmüş, olumsuzluklar yaşayan kişilerin söylediklerini neden en çok ilgiyle dinlersiniz?

Katılımcıların çoğu, kendilerini şiddet görmüş, olumsuzluklar yaşamış kadınlara kendilerini daha yakın hissettiklerinden, onlara acıma duygusu beslediğinden, onların görmüş geçirmiş olduğunu düşündüklerinden dolayı en çok ilgiyle dinleme nedenleri olduğunu belirtmektedir.

Sonda: Daha çok bu konuları (zorluk, sıkıntı) konuşmanızın sebepleri ne olabilir?

Katılımcılar, sıkıntıların konuşulmasının kendilerini rahatlattığı, hem sözlerinin dinlenmesini sağladığı hem de çözüm bulmak için insanların kendilerine yardım etmeye çalıştıklarını ve böylece kendilerini değerli hissettiklerini belirtmektedir.

4. "Gündelik yaşamda şehir/kent merkezlerine ne sıklıkla gidersiniz? Gidiş amacınız nedir?"

Katılımcılar, gündelik yaşamda şehir/kent merkezlerine,akraba ziyaretleri, çocuklarının okul görüşmeleri, gündelik ev ihtiyaçlarına yönelik pazar alışverişleri ve hastaneler için dışarı çıtıklarını söylemektedir.

Sonda: Şehir merkezlerine kimlerle gidersiniz? Yalnız hiç gittiniz mi?

Katılımcılar genellikle şehir merkezine yalnız gitmediklerini belirterek, eş, akraba, komşu kadınlar ve çocuklarıyla gidebildiklerini eklemektedir.

Sonda: Neden şehir merkezine yalnız gitmezsiniz?

Katılımcılar, genelde kendilerinin şehir merkezlerinin ortamından korktuklarını, çekindiklerini,böyle yerlerde kendilerini yalnız hissettiklerinden, yanlarında hep birilerinin olmasına ihtiyaç duymakta, hep birileriyle dışarı çıkmak zorunda hissettiklerini; kent/şehir merkezine yalnız çıkıldığında, yakın akraba, komşu ve mahalle kadınların nereye gidiyor soruları ve bakışları, tavırları ve sorgulamasından çekindiklerinden yalnız gidemediklerini belirtmişlerdir.

Sonda: Anlattığınız bu kaygıları hissetmeden kent/şehir merkezine gittiğiniz oldu mu? Olduysa sebebi?

Katılımcılarşehir/kent merkezine yalnız gitme hususunda, genellikle hastalanıp hastaneye gittiklerinde kendilerini rahat hissettiklerini belirtmektedirler. Bunda insanların tavırları kendilerini rahatsız etmediği gibi çevre tarafından olumlu karşılandığı ve desteklendiği yönünde görüş bildirmişlerdir.

Sonda: Bu durum sizde hastaneye gitmek ve hastane hakkında nasıl duygular oluşturdu?

Katılımcılar çoğunlukla, hastalıkları nedeniyle hastaneye gitmeyi, davranışlarını rahatlatan ve kendilerini daha bağımsız, özgür hissettiren şeyler olduğunu belirtmişlerdir.

5. "Gündelik yaşamda evde kendinizi değerli ve özel hissettiğiniz zamanlar hangi zamanlardır?"

Katılımcılar kendilerine özel hediye alındığında, yaptıkları işler onaylanıp takdir edildiğinde, yapılacak işler hakkında fikirleri sorulduğunda ve hasta olduklarında yardım edildiğinde kendilerini değerli gördüklerini belirtmişlerdir.

Sonda: Çevre, akraba ve komşularla ilişkilerinizde kendinizi özel hissettiğiniz zamanlar hangi zamanlardır?"

Katılımcıların çoğu genellikle oturmalara ve günlere davet edildiklerinde kendilerini özel hissettiklerini belirtmektedir. Ayrıca, hastayken ziyaret edilip ev işlerine yardımcı olunduğunda kendilerini özel ve değerli hissettiklerini eklemektedir. 


\section{Tartışma ve Sonuç}

Anadolu kadını, Anadolu topraklarındaki yaşam kültürünün şekillendirdiği kadın yapısıdır. Bulgulardan yola çıkarak, yaşamda kadına biçilen rol, kadının davranış ve düşünce alt yapısını oluşturuyor denilebilir. Ekonomik bağımsızlığı olmayan kadınların yaşam içerisinde kısır döngüsel yaşam ve tartışmalar içerisinde olduğunu ve bu yaşantıda kadının kendisine yer bulabilmek için kendi benliğinden ödün vermek zorunda ve/veya isteğinde olmayı oluşturuyor. Yaşam başarısı biraz da bu acıların için de olmayı, acıları izlemeyi öngörüyor. Çevresel baskılardan veya anlayışlardan dolayı eğitimi hedef alamamış ya da eğitime yönlendirilmemiş kadınlar dünyayı ve kendisini tanımada küçük bir çevreye hapsolarak o çevrenin gözüyle kendisine bakmak zorunda kalıyor. Halbuki izole edilmiş kapalı bir kutunun hafifçe kapağını aralayıp ışı̆̆ın içeriyi aydınlatması gibi, kadını geliştirecek çeşitli uğraşılar ve haklarının farkında olması bütün yaşamını ve ortamı aydınlatacağını görmek gerekir.

\section{Kaynakça}

Anık, C. (2006). Bilgi sosyolojisine göre bilginin işlevi ve bir model denemesi. Bilig Güz, S. 39, 1-29

Bourdieu, P. (1986). Theforms of capital. J. Rihardson, Ed. Handbook of TheoryandResearchforSociology of Education. İçinde (s. 241-258). New York: GreenwoodPress.

Çeğin, G.,Tatlıcan, Ü., Arlı ve Göker E. (2007). Ocak ve Zanaat.İstanbul: İletişim Yayınları.

De Beauvoir, S. (1979). Kadın Evlilik Çağı (Çev. B. Onaran). İstanbul: Payel Yayınevi.

Erbaş, H. (1992). Sosyolojide fenomoloji. AÜ DTCF Araştırma Dergisi, Sayl, 14, 1, 159-166.

Soner, A. (2011). Yapı ve fail ilişkisinden hareketle ataerkil ideoloji ve toplumsal cinsiyet etkileşimini anlamak. İnönü Üniversitesi Sanat ve Tasarım Dergisi. Özel Sayı Cilt.1.”Women as a Category of Science: TheFourth International Women `s Symposiumon Literature, Language, Culture, Art, Landscapeand Design Studies" 4-5-6 May 2011, Inonu University, Malatya, Turkey.

Yıldırım ve Şimşek (2013). Sosyal Bilimlerde Nitel Araştırma Yöntemleri.Ankara: Seçkin Yayıncılık. www.huseyinbal.com/makaleler/Fenomenolo-Etnomedodoloji.pdff. 26.09.2013 tarihinde erişilmiştir. 